\title{
The incidence and mortality of multiple sclerosis in south east Wales
}

\author{
A HENNESSY, R J SWINGLER, D A S COMPSTON \\ From the Section of Neurology, Department of Medicine, University of Wales College of Medicine, Cardiff, UK
}

SUMMARY The incidence of multiple sclerosis was shown to be $8 \cdot 2 / 10^{5} /$ year (definite or probable $5 \cdot 4$ and suspected $2 \cdot 8 / 10^{5} /$ year) during a 3 year prospective study carried out in an area of south east Wales which has a high prevalence of the disease $\left(120 / 10^{5}\right)$. Mortality in affected individuals who were prevalent at the start of the survey was $3 \cdot 1 / 10^{5} /$ year; many deaths resulted from direct complications of multiple sclerosis but $38 \%$ were due to unrelated causes. The rate at which new cases were identified approximately matched deletions from the register arising from death, outward migration and other causes so that prevalence did not change significantly during the survey (1985-1988).

Statistics relating to the frequency and distribution of multiple sclerosis have been used both in planning the provision of services and in seeking to understand the cause of the disease. Regional variations in prevalence and alterations in the number of cases identified in any one area with time have repeatedly been documented; ${ }^{1}$ these may reflect true alterations in the frequency of multiple sclerosis but also could have arisen from variations in clinical vigilance and changes in the application of criteria used for classification and diagnosis. The most reliable statistics from which to make comparisons on regional or temporal variations in disease frequency are the rates for incidence and mortality; these can best be determined prospectively in an area where prevalent cases have already been identified. The prevalence of multiple sclerosis was documented in south east Wales on 1 January $1985 ;^{2}$ the incidence and mortality is now reported for the same area in the triennium 1985-1988.

\section{Methods}

A list of individuals, at one time living in south east Wales, in whom the diagnosis of multiple sclerosis had been made was compiled from the departmental diagnostic index (available from 1946) the Hospital Activity Analysis (available from 1967), information supplied by local general practitioners, membership lists of the local multiple sclerosis societies, and community services. The resources of the Family Practitioner

Address for reprint requests: Professor D A S Compston, University of Cambridge Clinical School, Addenbrooke's Hospital, Hills Road, Cambridge CB2 2QQ, UK.

Received 6 January 1989.

Accepted 10 March 1989
Committee and the National Health Service Central Register were used to ascertain which of these individuals were no longer alive or had moved away from the study area. Based on personal interview or existing medical records the remainder were classified as having definite, probable or suspected multiple sclerosis on 1 January 1985 , as previously reported. ${ }^{2}$ In the first survey, the year of diagnosis was recorded both for living and dead patients and this information was used to estimate incidence rates from 1947-1984. Prevalent cases were "flagged" at the Office of Population Censuses and Surveys and all subsequent deaths were therefore notified. Changes of address were identified using local resources including contact with general practitioners and the Family Practitioner Committee. Clinical status was reviewed in survivors between January 1985 and December 1987 in the light of information gathered in the course of routine hospital care but attempts were also made formally to review the diagnosis in cases originally classified as having suspected multiple sclerosis. Since in the initial survey over $95 \%$ of prevalent cases were identified through referral to one or other of the three local neurologists, cases incident between 1985-1988 were identified prospectively by reviewing the diagnoses in every patient referred as an out patient or for admission to the department of neurology at the University Hospital of Wales, the only hospital providing neurological services in the survey area. Cases were classified using clinical criteria $^{3}$ and additional laboratory procedures were not carried out for the purposes of the survey.

\section{Results}

Four hundred and forty one prevalent cases were identified in 1985 of whom 380 had definite or probable multiple sclerosis and 61 were suspected cases. Minor adjustments to the 1985 figures $^{2}$ were necessary on the basis of additional clinical information available in 1988. Three patients with clinically definite multiple sclerosis thought to have been dead 


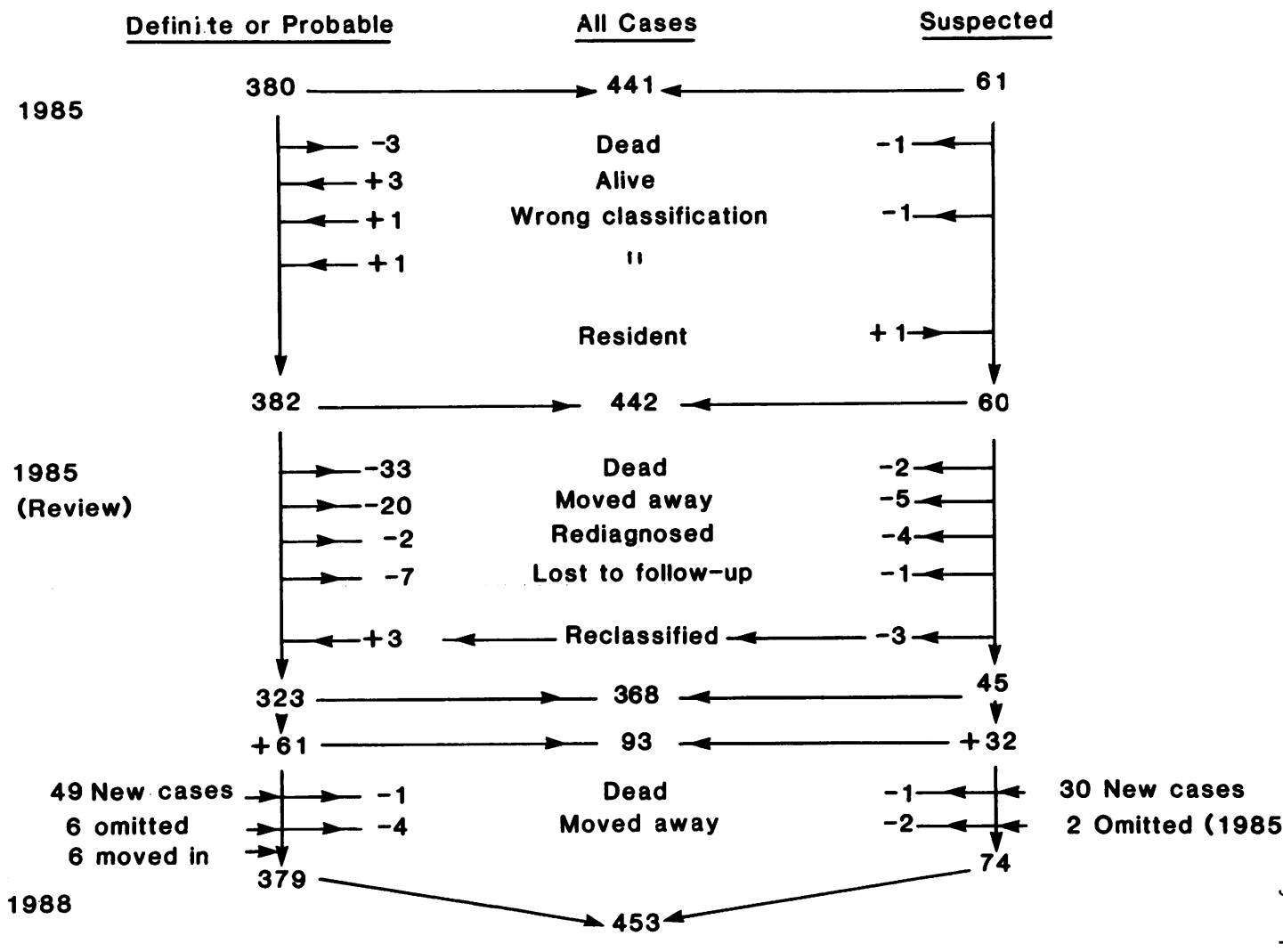

Fig Flow diagram showing the outcome in patients with multiple sclerosis prevalent in 1985 and classified as having definite 0 probable and suspected multiple sclerosis, together with those incident between 1985-1988 in each clinical category.

were subsequently found to have been alive in 1985 although all had died by 1 January 1988. Conversely, three others were wrongly classified as having been alive on 1 January 1985 . These errors therefore had no net effect on the figure quoted for prevalence in 1985 . One patient with suspected multiple sclerosis erroneously included in 1985 had in fact died prior to prevalence day. Two patients should have appeared on the 1985 list of clinically definite disease but had been incorrectly classified; one had been listed as having suspected multiple sclerosis and the other had not been included in either category. One patient with suspected multiple sclerosis who was thought to have moved away from the area prior to 1985 was subsequently found to be resident. The number of clinically definite or probable and suspected cases prevalent in 1985 should therefore have been 382 and 60 respectively (fig).

Thirty three of 382 definite or probable cases had died by 1988 and 20 had moved out of the area; in two other patients the diagnosis had been revised to hereditary spastic paraplegia and seven, examined prior to the earlier survey, could no longer be traced. Of the 60 suspected cases, two had died, five had moved, four were reclassified as having Ménière's disease, transient ischaemic attacks, Parkinsonism and a brachial plexus lesion respectively, and one could not be traced. Only three patients correctly classified as having suspected multiple sclerosis in 1985 were known to have developed clinically definite disease by 1988 .

Three hundred and sixty eight of 441 individuals from the 1985 register were therefore still prevalent in 1988 of whom 323 had clinically definite or probable disease and 45 had suspected multiple sclerosis (fig).

The diagnosis of definite or probable multiple sclerosis was made in 61 patients between 1985-1988. One of these subsequently died and four moved out of the area so that 379 individuals with definite or probable multiple sclerosis were prevalent on 1 January 1988. Multiple sclerosis was suspected in 32 cases presenting between 1985 and 1988 of whom one subsequently died and two moved away; 74 individuals with suspected multiple sclerosis were 
Table 1 Prevalence, incidence and mortality rates for multiple sclerosis in 1985 and 1988

\begin{tabular}{lcc}
\hline & 1985 & 1988 \\
\hline Prevalence $\left(\times 10^{5}\right)$ & 117 & 120 \\
All cases & 101 & 100 \\
Clinically definite/probable & 16 & 20 \\
Suspected & - & $8 \cdot 2$ \\
Incidence $\left(\times 10^{5} /\right.$ year $)$ & - & $5 \cdot 4$ \\
Clinically definite/probable & - & $2 \cdot 8$ \\
Suspected & - & $2 \cdot 1$ \\
Mortality $\left(\times 10^{5} /\right.$ year $)$ & - & $0 \cdot 2$ \\
Clinically definite/probable & - & 6.6 \\
Suspected & & \\
Deletions from register $\left(\times 10^{5} /\right.$ year $)$ & \\
\hline
\end{tabular}

therefore prevalent on 1 January 1988 (fig). The revised prevalence rate was $453 / 376718$ (120/10'; definite or probable $100 / 10^{5}$; suspected $20 / 10^{5}$ ) using the 1981 population census figures as denominator compared with $442 / 3766718\left(117 / 10^{5}\right.$; definite or probable $101 / 10^{5}$; suspected $16 / 10^{5}$ ) in 1985 (table 1 ).

The incidence of definite, probable or suspected multiple sclerosis between $1985-1988$ was $8 \cdot 2 / 10^{5} /$ year. Age and sex related rates are shown in table 2. Of the 61 cases incident between 1985 and 1988, 49 were diagnosed after 1 January 1985, six had previously been diagnosed but were not identified for the purposes of the first survey, and six with established multiple sclerosis had moved into the survey area between 1985 and 1988 . Of the 32 incident cases with suspected multiple sclerosis, 30 were newly diagnosed whereas two had inadvertently been omitted from the 1985 survey.

Thirty five of $442\left(3 \cdot 1 / 10^{5} /\right.$ year $)$ patients with definite, probable or suspected multiple sclerosis, prevalent in 1985, were known to have died during the ensuing 3 years. Despite this being lower than the observed incidence rate, the number of prevalent cases did not alter significantly between 1985-1988 since patients with definite, probable or suspected multiple sclerosis removed from the register between 19851988 as a result of death, reclassification, outward migration or loss to follow up $\left(74 ; 6 \cdot 6 / 10^{5} /\right.$ year $)$ nearly balanced the incident cases $\left(93 ; 8 \cdot 2 / 10^{5} /\right.$ year $)$. By assuming that the average patient had been seen at a random time during their illness, the duration of disease prior to death was previously estimated to be approximately 33 years (twice the interval between year of onset and the 1985 prevalence day), but this figure had wide confidence limits. Applying the same principle to the figures available for 1988 produced an estimate for disease duration of 30 years. This compares with intervals from estimated year of onset or diagnosis to death from all causes, in $31 / 37$ patients registered between 1985-1988 and dead by 1 January 1988 in whom these details were available, of 21.7 and $17 \cdot 3$ years respectively (table 3 ). The recorded cause of death, usually registered without necropsy information, was interpreted as being directly attributable to multiple sclerosis in 20/37 (usually pneumonia), indirectly related in a further two, unrelated in 14/37 and not recorded in $1 / 37$.

\section{Discussion}

The incidence of multiple sclerosis in a high prevalence area was shown prospectively to be $8.2 \times 10^{5} /$ year between 1985-1988; this estimate was based upon the number of newly identified cases and therefore

Table 2 Age at diagnosis (years) in cases incident between 1985-1988

\begin{tabular}{|c|c|c|c|c|c|c|c|}
\hline & & \multicolumn{2}{|c|}{ Definite/probable } & \multicolumn{2}{|c|}{ Suspected } & \multicolumn{2}{|c|}{ All cases } \\
\hline & & $\overline{\text { Male }}$ & Female & $\overline{\text { Male }}$ & Female & Male & Female \\
\hline $\begin{array}{r}0-10 \\
11-20 \\
21-30 \\
31-40 \\
41-50 \\
51-60 \\
61-70 \\
71-80\end{array}$ & $\begin{array}{c}\text { (years) } \\
\text { " } \\
" \\
" \\
" \\
"\end{array}$ & $\begin{array}{l}0 \\
0 \\
1 \\
5 \\
2 \\
7 \\
5 \\
1\end{array}$ & $\begin{array}{r}0 \\
1 \\
6 \\
12 \\
10 \\
10 \\
1 \\
0\end{array}$ & $\begin{array}{l}0 \\
0 \\
3 \\
3 \\
2 \\
2 \\
0 \\
0\end{array}$ & $\begin{array}{r}0 \\
0 \\
5 \\
10 \\
5 \\
2 \\
0 \\
0\end{array}$ & $\begin{array}{l}0 \\
0 \\
4 \\
8 \\
4 \\
9 \\
5 \\
1\end{array}$ & $\begin{array}{r}0 \\
1 \\
11 \\
22 \\
15 \\
12 \\
1 \\
0\end{array}$ \\
\hline Total & & 21 & 40 & 10 & 22 & 31 & 62 \\
\hline
\end{tabular}

Table 3 Duration of disease from onset/diagnosis (years) in patients with multiple sclerosis dying between 1985-1988

\begin{tabular}{|c|c|c|c|c|c|c|c|}
\hline & & \multicolumn{2}{|c|}{ Definite/probable } & \multicolumn{2}{|c|}{ Suspected } & \multicolumn{2}{|c|}{ All cases } \\
\hline & & Male & Female & Male & Female & $\overline{\text { Male }}$ & Female \\
\hline $\begin{array}{l}0-10 \\
11-20 \\
21-30 \\
31-40 \\
41-50 \\
\text { Not know }\end{array}$ & $\begin{array}{c}\text { (years) } \\
" \\
" \\
\text { Nn }\end{array}$ & $\begin{array}{l}1 / 2 \\
1 / 0 \\
1 / 2 \\
2 / 1 \\
0 / 0 \\
1 / 1\end{array}$ & $\begin{array}{l}6 / 8 \\
6 / 8 \\
5 / 4 \\
7 / 4 \\
2 / 2 \\
3 / 3\end{array}$ & $\begin{array}{l}0 / 0 \\
0 / 0 \\
1 / 1 \\
0 / 0 \\
0 / 0 \\
0 / 0\end{array}$ & $\begin{array}{l}0 / 0 \\
0 / 0 \\
1 / 1 \\
0 / 0 \\
0 / 0 \\
0 / 0\end{array}$ & $\begin{array}{l}1 / 1 \\
1 / 1 \\
2 / 3 \\
2 / 1 \\
0 / 0 \\
1 / 1\end{array}$ & $\begin{array}{l}6 / 8 \\
6 / 8 \\
6 / 5 \\
7 / 4 \\
2 / 2 \\
3 / 3\end{array}$ \\
\hline \multicolumn{2}{|c|}{$\begin{array}{l}\text { Not known } \\
\text { Total }\end{array}$} & $6 / 6$ & $29 / 29$ & $1 / 1$ & $1 / 1$ & $7 / 7$ & $30 / 30$ \\
\hline
\end{tabular}


includes individuals with established multiple sclerosis who moved into the survey area, those in whom the presentation of pre-existing symptoms had been delayed for a variety of reasons, those in whom an alternative diagnosis had been revised, and patients whose symptoms developed for the first time during the period of study. Mortality was $3.1 \times 10^{5} /$ year over the same period but if this figure is also adjusted to include all deletions from the register of cases prevalent in 1985, "incidence" and "mortality" are seen almost to be in equilibrium during the three year period.

These statistics need to be taken in the context of regional and temporal trends in the frequency of multiple sclerosis. Prevalence is the product of incidence or mortality and disease duration and will rise with an increase in any of these variables. The introduction of measures which influence survival from multiple sclerosis will have several effects on the frequency of the disease. An increased duration of disease arising from improved management of the complications will be followed by a rise in prevalence. Measures which rapidly alter survival, such as the introduction of antibiotics in the 1940s, will reduce annual mortality but this will increase with time as the cohort with improved survival succumbs to late complications of the disease or dies from unrelated causes. In the long term age specific mortality rates will alter, most deaths occurring in older patients, whereas mortality attributable to multiple sclerosis will be persistently reduced in the population of young adults who have the highest incidence of the disease. A significant alteration in age adjusted mortality from multiple sclerosis has in fact been observed in the United Kingdom over the last four decades. ${ }^{1}$ An approximate measure of duration can therefore be obtained by comparing age specific rates for incidence and mortality. From a consideration of all these statistics it is likely that most of the reported temporal trends in prevalence have arisen entirely from increased duration of the disease.

Incidence is difficult to determine accurately since the interval between onset of symptoms and diagnosis is not constant and methods for identifying new cases or the application of diagnostic criteria and laboratory aids to diagnosis have changed with time. Errors occur even in the most careful of surveys. In our initial study 10/441 individuals were wrongly classified, clinically or demographically, and eight further cases were subsequently identified which should have appeared on the 1985 register. Surprisingly only three of 61 suspected cases were known to have developed further symptoms leading to reclassification as clinically definite or probable multiple sclerosis. This may be because we were not sufficiently rigorous in achieving follow up prior to the 1988 reclassification and the figure may represent an underestimate; alternative interpretations, apart from the possibility that the original episode was incorrectly diagnosed, are that these patients have demyelination in an isolated form which never recurs or benign multiple sclerosis in which relapses occur infrequently and subclinically. Prolonged follow up would be needed to resolve these issues. Alterations in mortality rate should also be interpreted with caution since patients with multiple sclerosis often die from unrelated causes and notification of contributory or coincidental conditions is omitted.

Rates for the incidence and mortality of multiple sclerosis need to be derived prospectively building upon a baseline register of prevalent cases. Reliable statistics depend upon prolonged epidemiological scrutiny in the survey area ${ }^{45}$ and relatively few studies are therefore available. However, it is of particular importance to have available serial estimates of incidence since if methodological artefacts have been eliminated, a change in rate strongly suggests an alteration in the biological factors favouring development of the disease. Comparisons of incidence and mortality are also important since disequilibrium, whether or not either rate has been serially determined over a prolonged period, also implicates a recent change in aetiological conditions. The importance of this type of analysis is seen in north east Scotland ${ }^{6-8}$ in some parts of which both rates are reported to be falling ${ }^{9}$ following a prolonged period of hig prevalence. ${ }^{10-12}$

\section{References}

1 Swingler RJ, Compston DAS. The distribution of multiple sclerosis in the United Kingdom. $J$ Neurol Neurosurg Psychiatry 1986;49:1115-24.

2 Swingler RJ, Compston DAS. The prevalence of multiple sclerosis in south east Wales. J Neurol Neurosurg Psychiatry 1988;51:1520-4.

3 Poser CM, Paty DW, Scheinberg L, et al. New diagnostic criteria for multiple sclerosis: guidelines for research protocols. Ann Neurol 1983;13:227-31.

4 Hammond SR, McLeod JG, Millingen KS, et al. The epidemiology of multiple sclerosis in three Australian cities: Perth, Newcastle and Hobart. Brain 1988;111: $1-25$.

5 Hammond SR, English DR, de Wytt C, et al. The contribution of mortality statistics to the study of multiple sclerosis in Australia. J Neurol Neurosurg Psychiatry 1989;52:1-7.

6 Shepherd DI, Downie AW. Prevalence of multiple sclerosis in north east Scotland. $\mathrm{Br}$ Med J 1978;2: 314-6.

7 Shepherd DI, Downie AW. A further prevalence study of multiple sclerosis in north east Scotland. J Neurol 
Neurosurg Psychiatry 1980;43:310-5.

8 Downie AW, Phadke JG. The chief scientist reports. Multiple sclerosis in north east Scotland. Health Bulletin (Edinb) 1983;42(3):151-6.

9 Cook SD, Cromarty MB, Tapp W, et al. Declining incidence of multiple sclerosis in the Orkney Islands. Neurology 1985;35:545-51.

10 Sutherland JM. Observations on the prevalence of mul- tiple sclerosis in northern Scotland. Brain 1965;79: 635-54.

11 Fog M, Hyllested K. Prevalence of disseminated sclerosis in the Faroes, the Orkneys and Shetland. Acta Neurol Scand (suppl) 1966;42 (suppl 19):9-11.

12 Poskanser DC, Prenney LB, Sheridan JL, Kondy JY. Multiple sclerosis in the Orkney and Shetland Islands. J Epidemiol Community Health. 1980;34:229-39. 